\title{
Defining Optimum Location of Shear Wall in an Irregular Building by Considering Torsion
}

\author{
Rajiv Banerjee, J. B. Srivastava
}

\begin{abstract}
In this paper, the optimum or suitable location of shear wall in a high rise irregular shaped building is determined. The criteria of choosing suitable location are well mentioned with suitable examples. We have tested several models in dynamic analysis with the help of ETABS ver. 16. Both Time History and Response Spectrum Methods are performed in the analysis. The paper clearly specifies the causes of torsion in a high rise building as well as it also specifies the ways in which we can control the torsion and storey displacement with the help of shear wall in the high rise buildings.
\end{abstract}

Keyword: Centre of Stiffness, Centre of Mass, Time History Analysis, Response Spectrum Analysis.

\section{INTRODUCTION}

The multi-storey buildings are vulnerable to wind and seismic forces. These forces have the capability to destabilise the structure within a matter of seconds. Thus, making a structure stiffer during these sudden calamities is very important. The lateral stability can be introduced in the building by providing shear walls. Shear walls are the planer structural elements possessing high structural stiffness. These are placed in high rise building with an intention to reduce storey displacement due to the lateral forces. The efficiency of shear wall is governed by its location in a building. When we talk about an irregular shaped building, defining optimum location becomes very difficult. This is because of the fact that, the irregular shaped buildings when subjected to lateral forces triggers torsion because of their geometry. In these cases provision of shear wall in danger zones can trigger more torsion in the building. The shear wall will be like, 'friend turned foe' for the building. Thus, it is very important to study the generation of torsion force in a high rise building. Along with that, we must not forget the use of shear wall, i.e. providing resistance against lateral forces. Thus, optimum location of shear wall can only be decided by considering the torsion generated in the building during the lateral forces. The following point will elaborate the cause of torsion in a high rise building - Before going in details, the following points will be worth noting:

- Centre of Mass - It is an assumed point in a building which has equal distribution of mass around itself in all direction. In other words, the point where the whole mass of the building is assumed to be concentrated is called centre of mass.

Revised Manuscript Received on April 27, 2020.

* Correspondence Author

Rajiv Banerjee*, Ph. D student, Dr. A.P.J. Abdul Kalam Technical University, Lucknow.

Dr. J. B. Srivastava, Professor, Institute of Engineering and Technology, Lucknow, India.

(C) The Authors. Published by Blue Eyes Intelligence Engineering and Sciences Publication (BEIESP). This is an open access article under the CC BY-NC-ND license (http://creativecommons.org/licenses/by-nc$\underline{\mathrm{nd} / 4.0 /)}$
- Centre of Stiffness/Rigidity - Like the centre of mass, centre of stiffness is also an assumed point in a building where the resultant stiffness of the building is assumed to be concentrated.

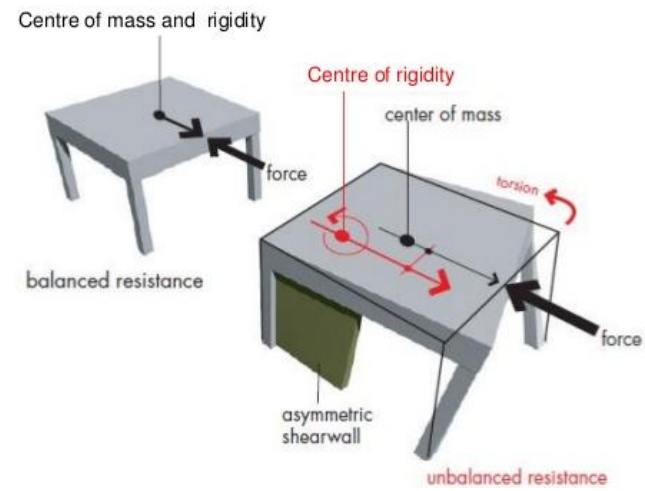

Fig. 1 Centre of Rigidity/Stiffness \& Centre of Mass (Source: www.slideshare.net)

A. Cause of torsion in building - When the centre of mass and centre of stiffness in a building do not coincide, this produces torsion. The change in the location depends on the irregularity in structure. The more are the irregularities, the more is chance of eccentricity (gap between the centre of mass and centre of stiffness). This condition is very common in irregular shaped buildings. Thus, the location of shear wall should be such that, it should not ignite more torsion in the structure.

Causes of dislocation of these points -

- When the stiffness in one part of the structure is dominant as compared to other areas in the structure, the centre of stiffness shift towards that area, causing an eccentricity in a structure.

- The stiffness can increase either through introduction of shear wall or in some of the cases; the building's irregular geometry causes self triggering of torsion when subjected to seismic forces.

\section{DEFINING THE CRITERIA FOR DETERMINING OPTIMUM LOCATION}

The location of the shear wall which will result in reduction of torsional forces as well as the storey displacement will be termed as the optimum location. If the location only exhibits reduction in displacement but produces huge torsion, that will not be considered as an optimum location.

\section{DETAILS OF THE TESTED MODELS}

\section{A. Geometrical Details}

- Length of bays in building frame (uniform) is $5 \mathrm{~m}$

- Cross- section of beam is $300 \times 450 \mathrm{~mm}$

- Cross-section of column is 350 X $750 \mathrm{~mm}$

\section{Published By:}

Blue Eyes Intelligence Engineering \& Sciences Publication 
- Thickness of slab is $150 \mathrm{~mm}$

- Thickness of Shear Wall is $230 \mathrm{~mm}$

- The grade of concrete and steel used in the models are M25 and Fe 415 respectively.

- The models are G+15 storey buildings with floor to floor height as $3 \mathrm{~m}$.

- The models are U Shaped and T Shaped (Irregular in Plan).

B. General Loading Details

- Dead Load at floor is $2 \mathrm{kN} / \mathrm{m}^{2}$

- Live Load at floor is $3 \mathrm{kN} / \mathrm{m}^{2}$

- Dead Load at beam is $6.9 \mathrm{kN} / \mathrm{m}$

C. Seismic Loading Details

- Response Spectrum Data from is as per IS 1893:2016 (Table -12) for seismic zone- IV.

- Time History Data for testing the models is considered from Array Recording Station, El Centro, U.S.A. for T Shaped Building and Nepal Earthquake Data for U Shaped Building.

\section{ANALYSIS DETAILS}

The analysis of the models will be done by ETABS ver. 16 by using the inbuilt data of Response Spectrum and Time History Analysis.

\section{MODEL LAYOUT}

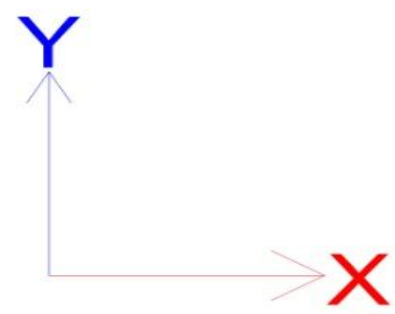

Fig. 2 Assumed Direction

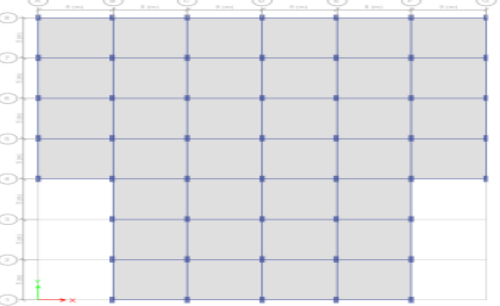

Fig. 3 Bare Frame T Shaped

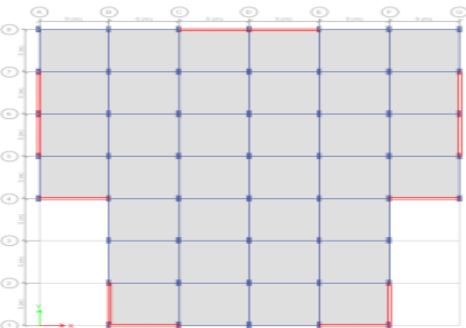

Fig. 4 Model 01 T Shaped

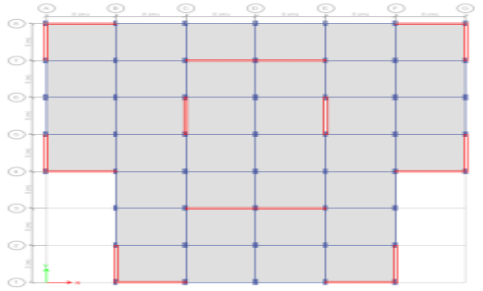

Retrieval Number: D6822049420/2020@BEIESP
Fig. 5 Model 02 T Shaped

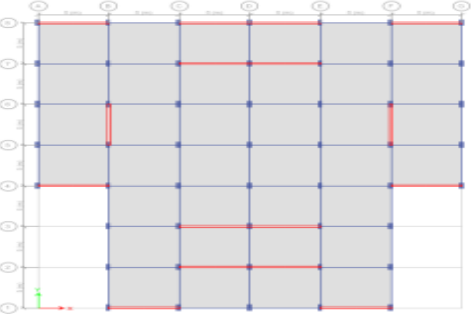

Fig. 6 Model 03 T Shaped

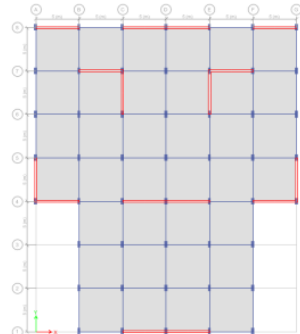

Fig. 7 Model 04 T Shaped

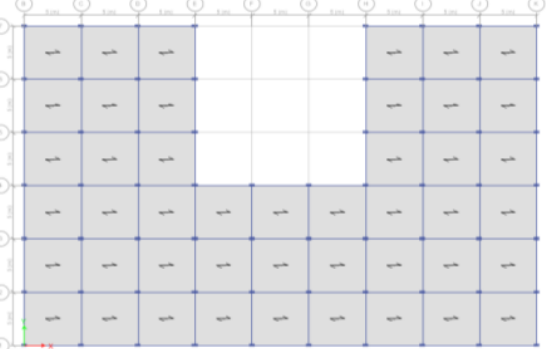

Fig. 8 Bare U Shaped

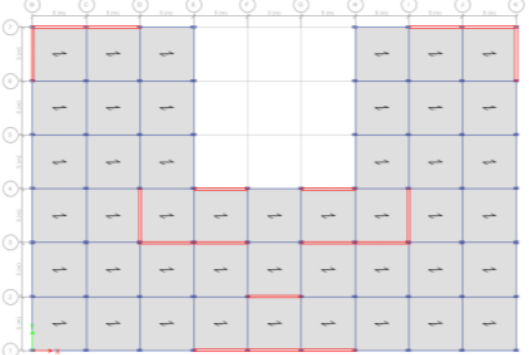

Fig. 9 Model 01 U Shaped

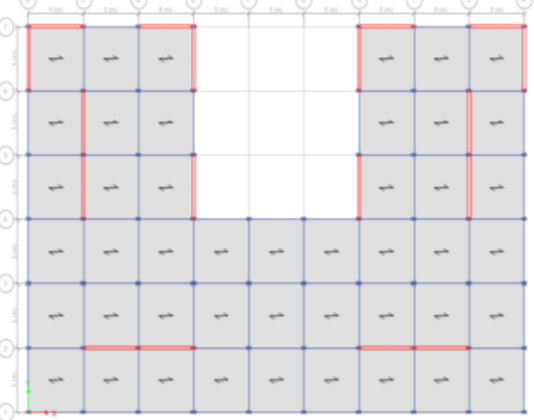

Fig. 10 Model 02 U Shaped 


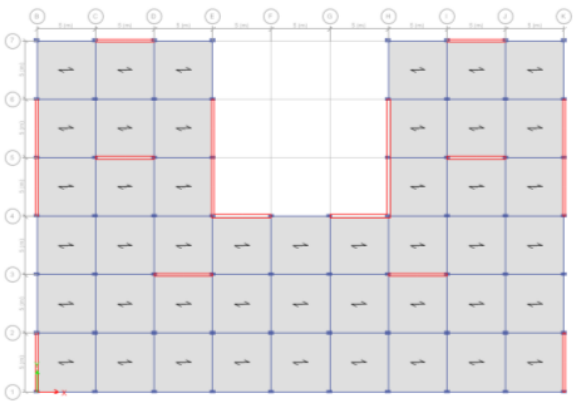

Fig. 11 Model 03 U Shaped

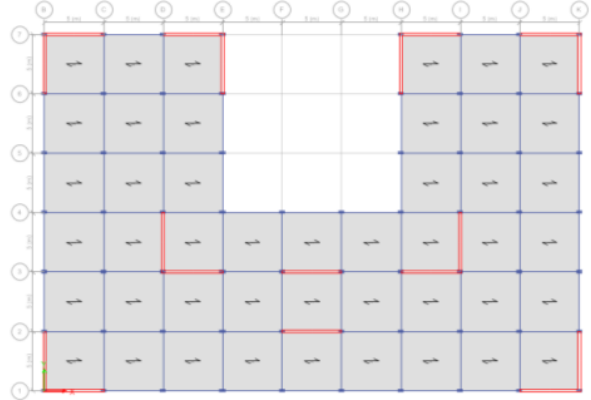

Fig. 12 Model 04 U Shaped

\section{COMPARATIVE STUDY}

\section{A. Base Shear \& Storey Displacement}

After the dynamic analysis from ETABS, we have the following comparative representation of the test models for base shear and storey displacement -

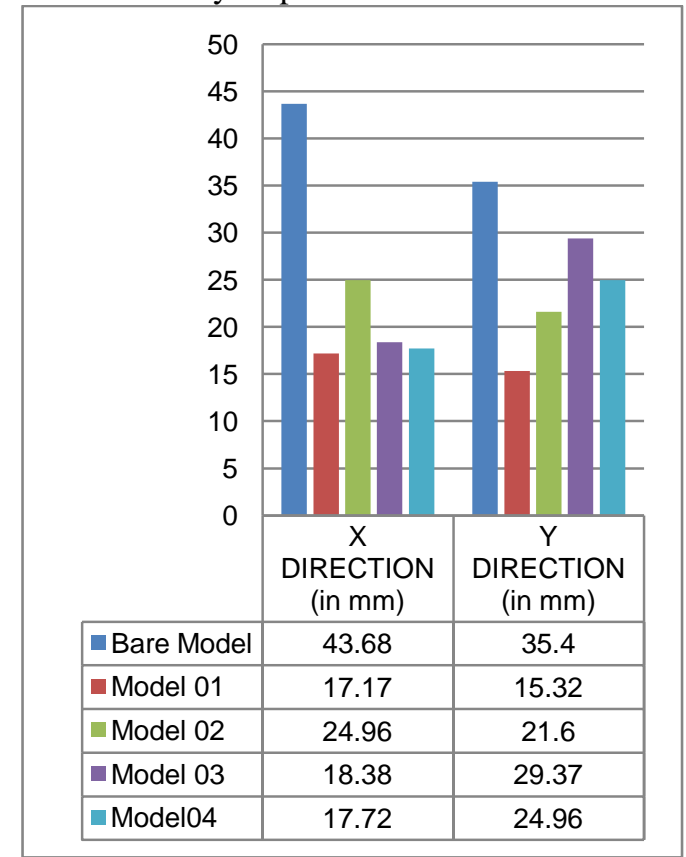

Fig. 13 Maximum Storey Displacment (Response Spectrum Analysis) - T Shaped

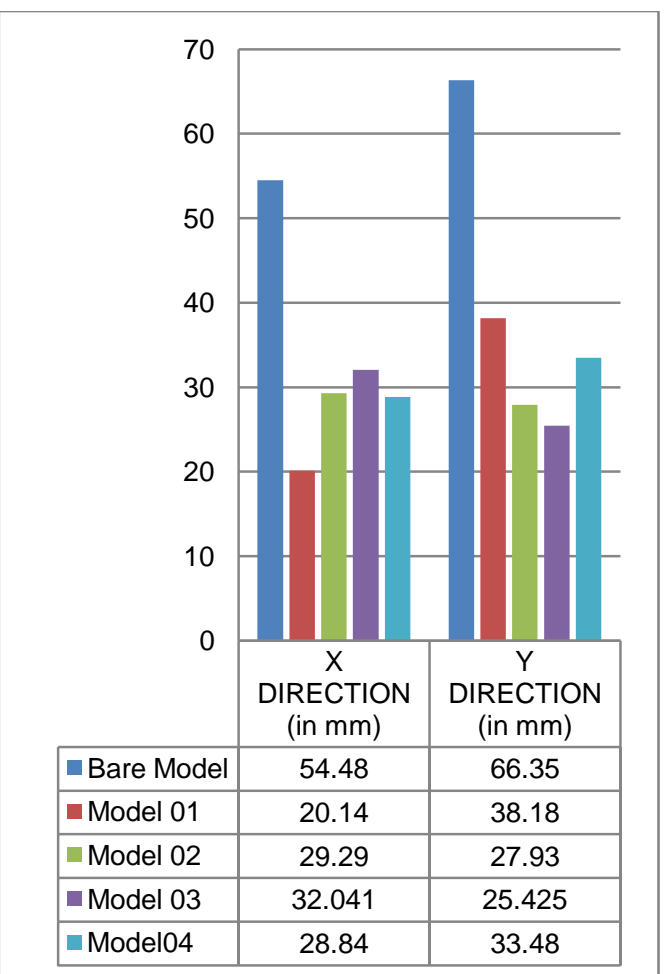

Fig. 14 Maximum Storey Displacment (Response Spectrum Analysis) - U Shaped

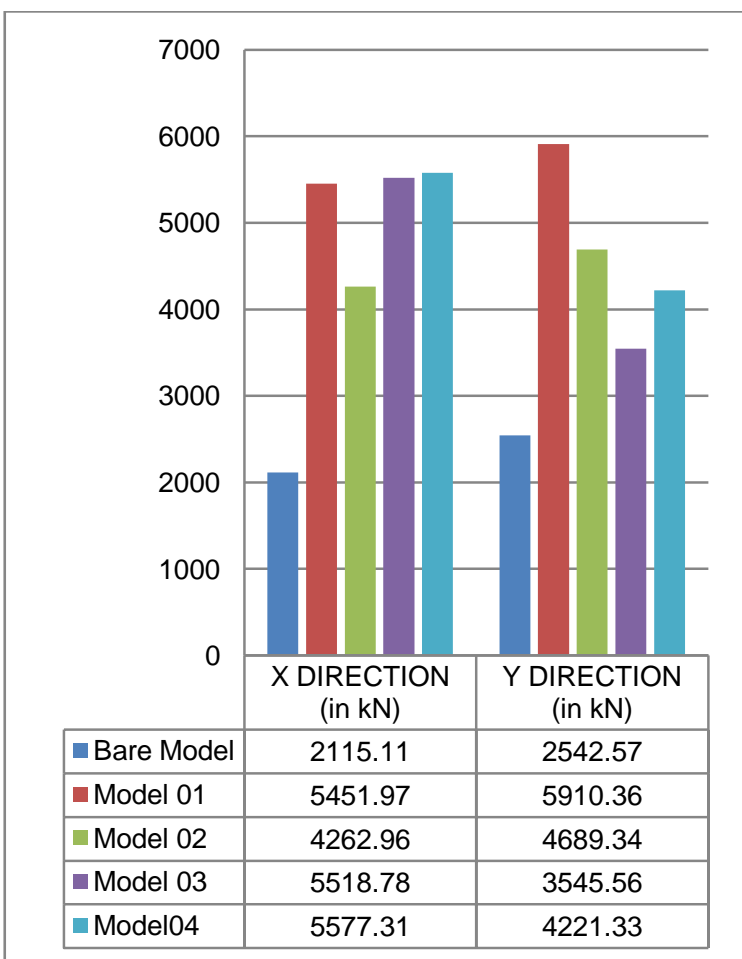

Fig. 15 Storey Shear (Response Spectrum Analysis) - T Shaped

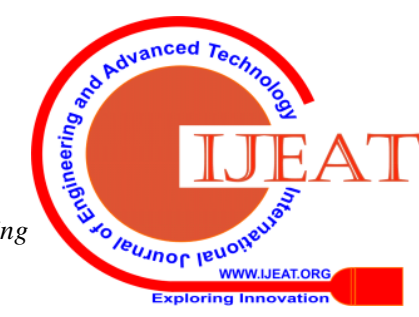


Defining Optimum Location of Shear Wall in an Irregular Building by Considering Torsion

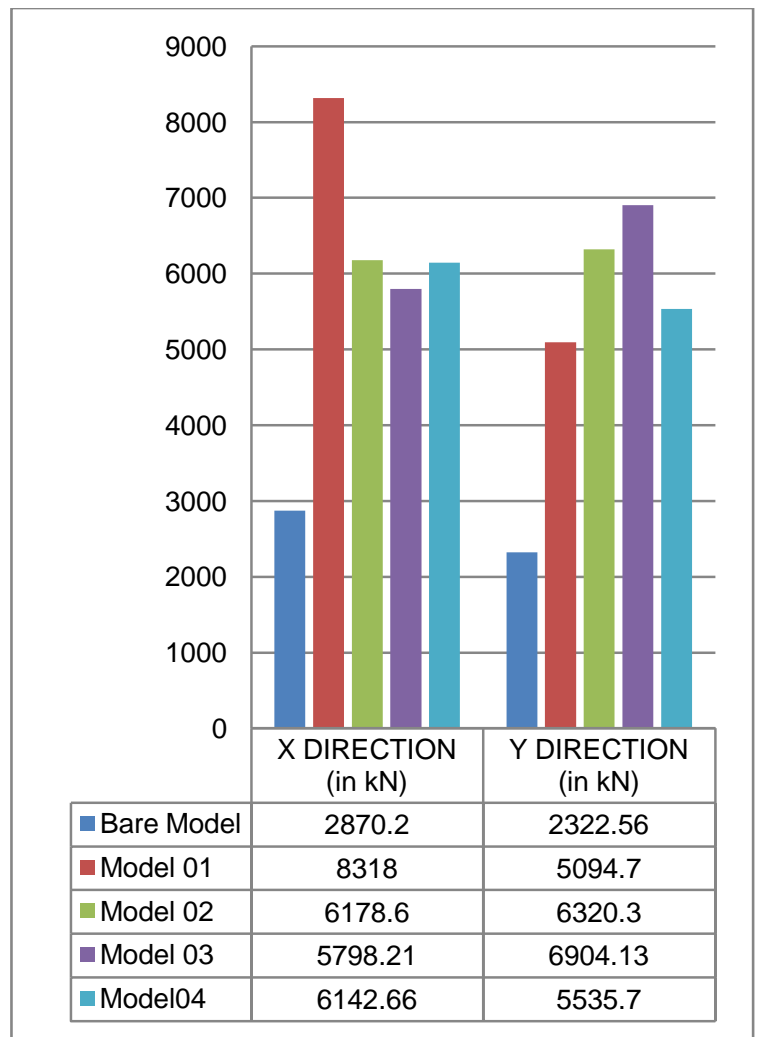

Fig. 16 Storey Shear (Response Spectrum Analysis) - U Shaped

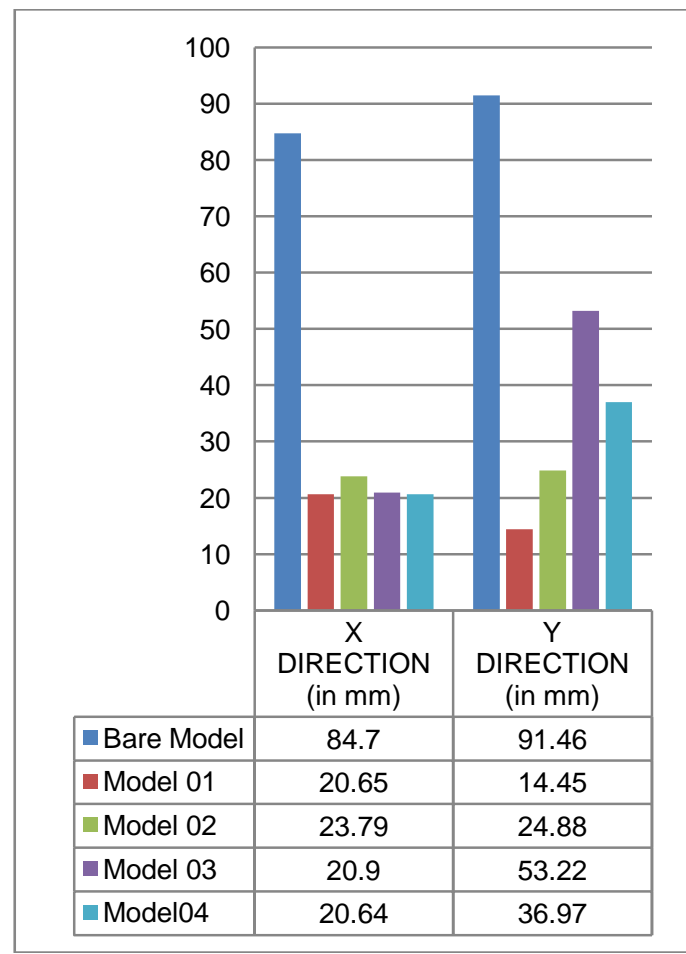

Fig. 17 Maximum Storey Displacement (Time History Analysis) - T Shaped

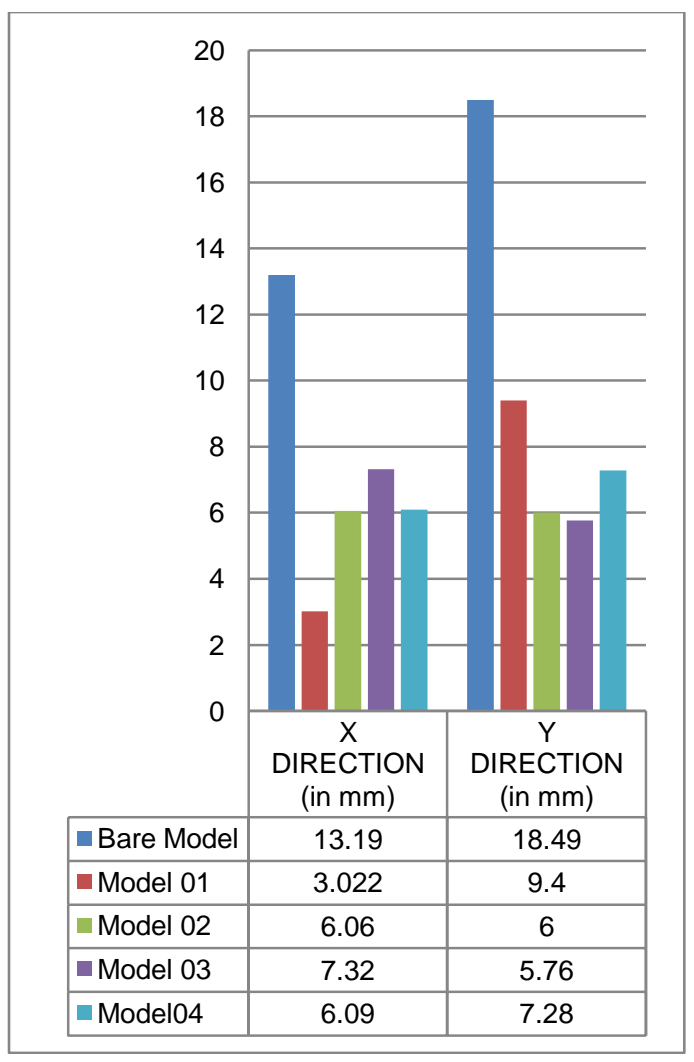

Fig. 18 Maximum Storey Displacement (Time History Analysis) - U Shaped

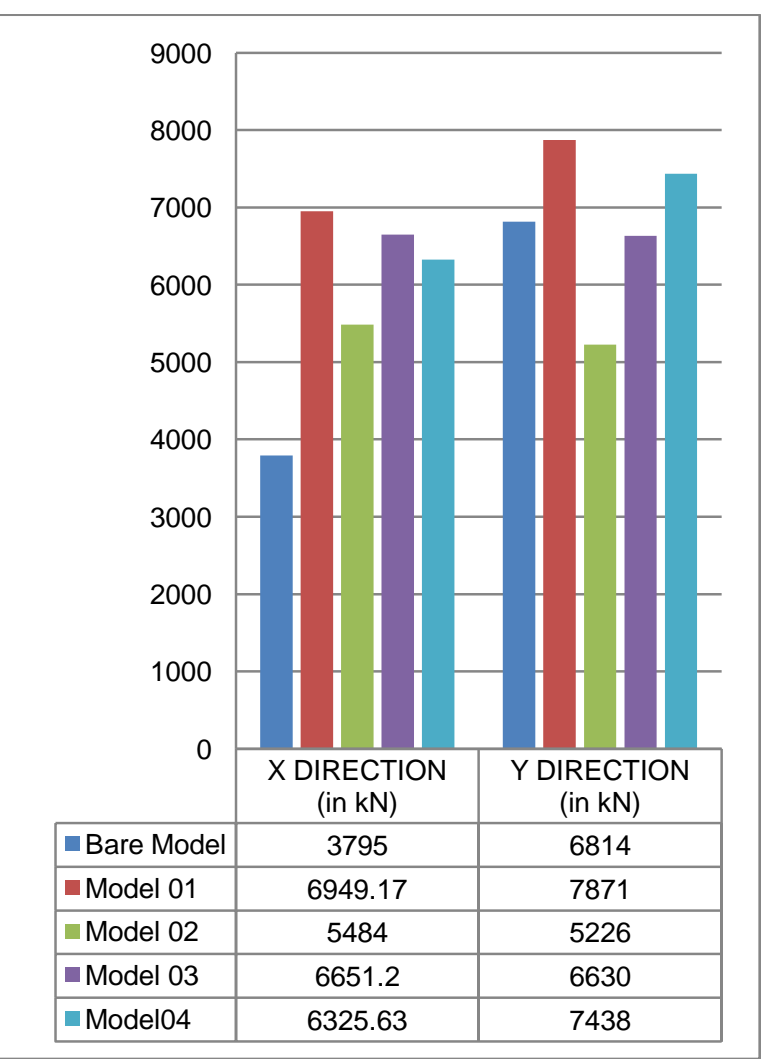

Fig. 19 Base Force (Time History Analysis) - T Shaped

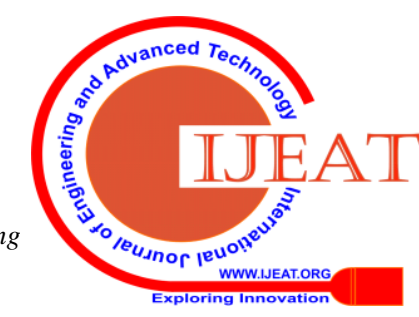




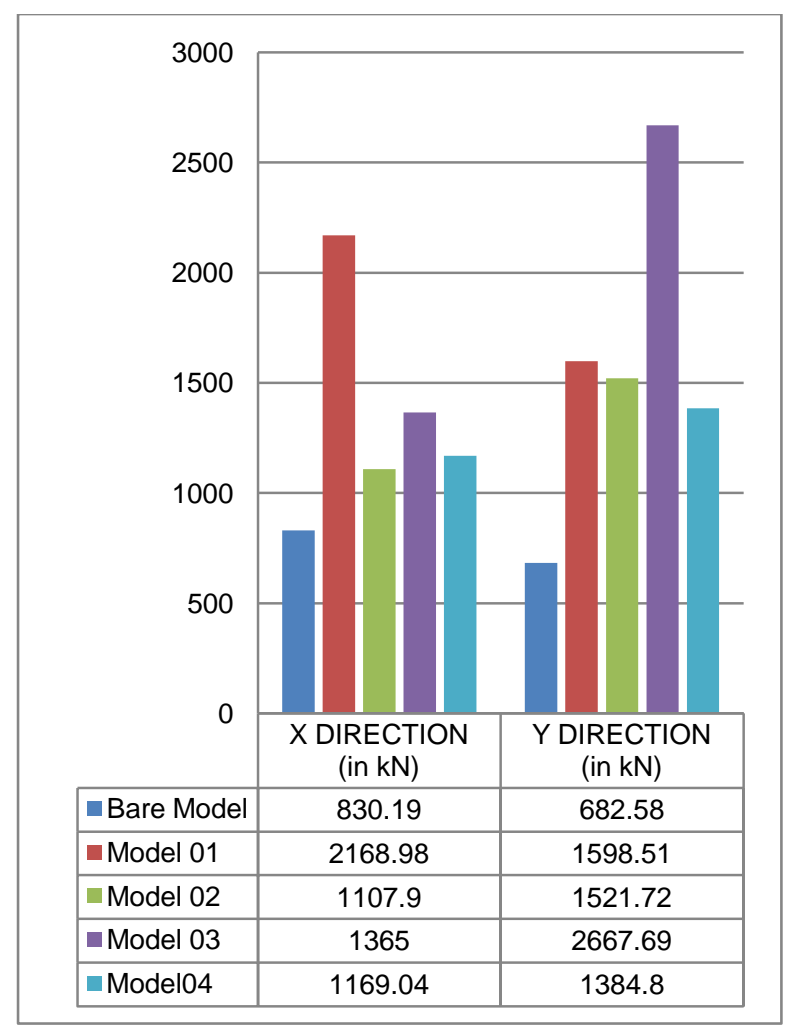

Fig. 20 Base Force (Time History Analysis) - U Shaped

\section{B. Eccentricity in Structure}

After the analysis from ETABS, we obtained that our Ushaped \& T-shaped test model were having an eccentricity along y-axis. Thus, in order to eliminate the eccentricity we have placed the shear wall at various locations elaborated above. The comparative representation is given below -

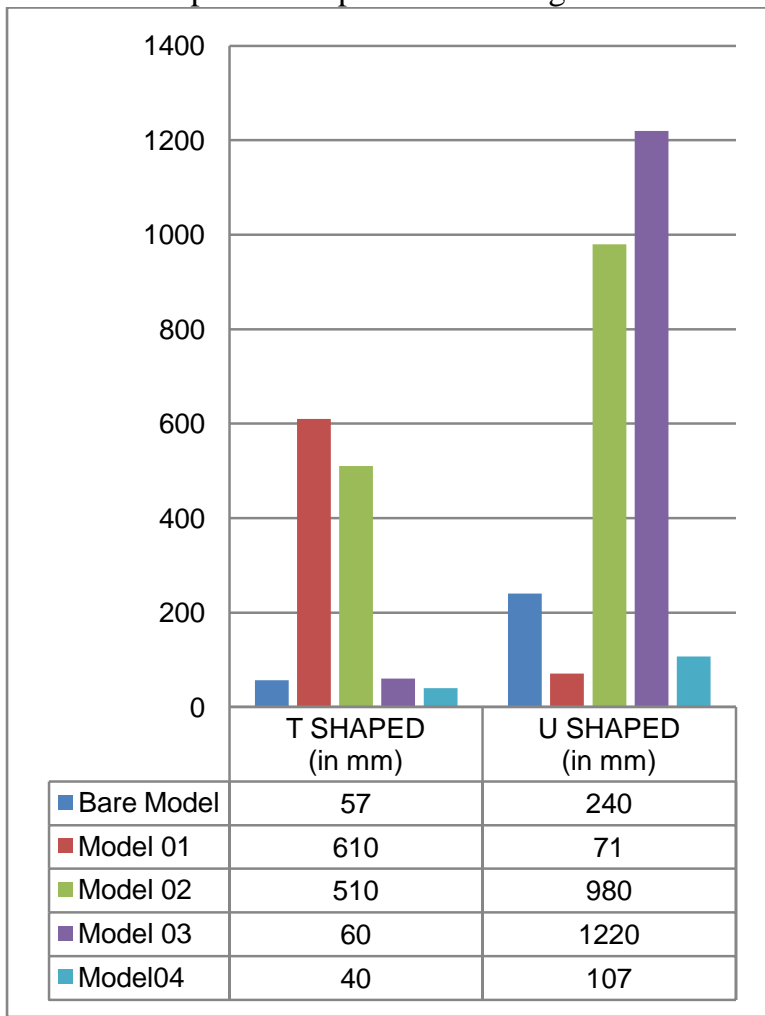

Fig. 21 Eccentricity (In Mm)

\section{RESULT}

From the comparative analysis, it was found that MODEL 04 of the T Shaped building \& MODEL 01 of U Shaped

Retrieval Number: D6822049420/2020@BEIESP

DOI: 10.35940/ijeat.D6822.049420

Journal Website: www.ijeat.org
Building from the test models were best in resisting both lateral displacement and torsion effects in the building.

\section{VIII. . CONCLUSION}

From the above points, it is concluded that shear walls are very important in high rise buildings in resisting lateral forces. But it is important to note that, the location of shear wall plays an important role in determining the efficiency of shear wall. If the location of shear wall is such that it causes an increase in torsional forces, it becomes the biggest enemy of the structure. Thus, one has to place the shear walls such that centre of mass and centre of stiffness of the structure should be as close as possible.

It is possible that, some configuration of shear walls can cause huge reduction in lateral displacements but it can also trigger huge amount of eccentricity which in turn cause torsional forces in the structure. Thus, a balance has to be set up in the configuration of shear such that both the lateral forces along with torsion are eliminated at a greater extent.

\section{REFERENCE}

1. Francisco Crisfaulli, Agustin Rebredo and Gonzalo Torrist, “ Consideration of Torsional Effects in the Displacment Control of Ductile Buildings", $13^{\text {th }}$ World Conference on Earthquake Engineering, Vacouver, B.C. Canada, August 1-6,2004, Paper No. 1111.

2. Richa Gupta, Alfia Bano, "Performance Evaluation of Various Geometries of Shear Wall in Buildings by Equivalent Static Judgement", International Journal of Innovative Technology andk Exploring Engineering, ISSN: 2278-3075, Volume - 8, Issue - 6S4, April 2009.

3. Ankan Kumar Nandi, Jairaj C, "Backstay Effects of Diaphragm in Tall Buildings", International Journal of Innovative Technology and Exploring Engineering, ISSN: 2278-3075, Volume - 9, Issue - 3, January 2020.

4. Ali Demir, Duygu Donmex Demir, Recep Turgul Erdem, Muhiddi Bagei, " Torsional Irregularity Effects of Local Site Classes in Multiple Storey Structures, International Journal of Recent Research and Applied Studies, ISSN: 2349-4891, August 2010.

5. Atif Zakaria, M. Shiva Rama Krishna, T. G. N. C. Vansi Krishna, Mirza Mahboob Baig, "Effects of the Accidental Eccentricty on regular and irregular buildings", International Journal of Innovative Technology and Exploring Engineering, ISSN: 2278-3075, Volume 8, Issue - 11, September 2019.

6. Nobua Takai, Michiko Shigefuji, Sudhir Rajaure, Subeg Bijukchhen, Masayoshi Ichiyanagi, Megh Raj Dhita and Tsutomu Sasatani, "Strong Ground Motion in the Kathmandu Valley during the 2015 Gorkha, Nepal Earthquake", Earth, Planets, Space (2016) 68:10, DOI: 10.1186/s40623-016-0383-7.

\section{AUTHORS PROFILE}
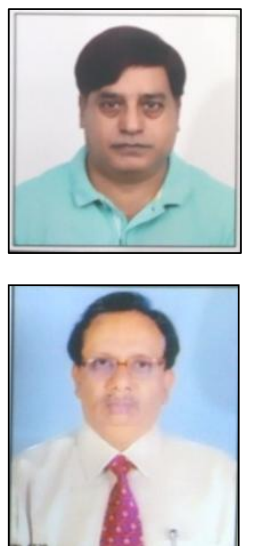

Rajiv Banerjee is a Ph. D student from Dr. A.P.J. Abdul Kalam Technical University, Lucknow. He retired from the post of Executive Engineer in Municipal Engineering Directorate, Govt. of West Bengal. He also has an experience of eight years in Academics and twenty seven years of experience in Construction Industry.

Dr. J. B. Srivastava is a Professor in Institute of Engineering and Technology, Lucknow, India. He started his teaching job as a Lecturer at Madan Mohan Malviya Engineering College, Gorakhpur. Later he was selected for Ph.D program in QIP scheme (GOI) at IIT - Roorkee in 1990 and completed Ph. D in Civil Engineering in 1995.

Published By:

Blue Eyes Intelligence Engineering \& Sciences Publication 